\title{
$\bullet \cdot$ IJCRR \\ Section: Healthcare \\ Additional Effect of Inspiratory Muscle Training Along with Aerobic Exercises in Overweight and Obese Individuals
} ISI Impact Factor (2019-20): 1.628 IC Value (2019): 90.81 $\operatorname{SJIF}(2020)=7.893$

\author{
Ketki Ponde ${ }^{1}$, Ronika Agrawal ${ }^{2}$, Shifa Anis Chini ${ }^{3}$, \\ Mehzabin Mehboob Amreliwala ${ }^{3}$
}

'Associate Professor, M.A.Rangoonwala College of Physiotherapy and Research, Pune, India; ${ }^{2}$ Principal, M.A.Rangoonwala College of Physiotherapy and Research, Pune, India; ${ }^{3}$ M.A. Rangoonwala College of Physiotherapy and Research, Pune, India.

\section{ABSTRACT}

Background: Obesity is known to be a major risk of a whole range of cardiovascular, metabolic and respiratory disorders. In obese individuals, respiratory muscles cannot function efficiently due to increased load on them that they are required to overcome and also due to reduction in their capacity. Respiratory muscle fatigue is a potential mechanism for impaired exercise tolerance.

Objective: The study aims to concentrate on finding whether adding Inspiratory muscle training (IMT) to their exercise protocol will be beneficial for overweight and obese individuals.

Methods: Overweight and obese individuals were divided into group A ( $n=30)$ and group B $(n=30)$ groups. BMI, inspiratory muscle strength and oxygen consumption (VO2max) were assessed pre and post-6-weeks of intervention. Group A performed inspiratory muscle training of 3 sets of 10 breathes followed by moderate intensity (Borg's RPE= 11 -13) of walking 20mins for 5 days/ week and progressing to 40mis at the end of 6 weeks. Group B performed only walking for 5 days/week for 6 weeks.

Results: Group A showed statistically highly significant improvement in 6 min walk distance $(p$ value=0.0001), PImax $(p$ value= 0.0001 ) and VO2 max ( $p$ value= 0.0035). Thus showing significantly better results in Group A. whereas group B did not show any change post-intervention ( $\mathrm{p} \geq 0.05)$.

Conclusion: Individuals who performed IMT along with walking showed greater improvement than the individuals who performed only walking.

Key Words: Inspiratory Muscle Training, Exercise performance, Obesity, Aerobic Exercise. Maximum Inspiratory Pressure

\section{INTRODUCTION}

Obesity is a complex, multifactorial condition that results from the interaction of genetic, metabolic, social, cultural and behavioural factors. ${ }^{1}$ It has been estimated that the global epidemic of overweight and obesity affects 1.7 billion people worldwide. ${ }^{2}$ In India 88 million individuals are overweight and 135 million individuals are obese. ${ }^{3}$ According to the classification of BMI for Asian population if Body Mass Index (BMI) is between $23-24.9 \mathrm{~kg} / \mathrm{m}^{2}$ the individual is considered as overweight, and if BMI is more than $25 \mathrm{~kg} / \mathrm{m}^{2}$ then they are considered as obese. ${ }^{4}$

Obesity is known to be a major risk of the whole range of cardiovascular, metabolic and respiratory disorders ${ }^{2}$. Several studies have shown that there are excess metabolic pertur- bations and increased cardiovascular risk factors at a lower value of BMI in Asian population as compared to the white population. Hence these days multiple studies and several guidelines are focusing more on early intervention with diet and physical activity in Asian ethnic groups to prevent and manage obesity-related non-communicable diseases. ${ }^{4}$ Due to the accumulation of adipose tissues in the abdomen, the physiology of breathing gets altered and diaphragmatic fibres get overstretched. This results in length-tension disadvantage with lower cardiorespiratory endurance which in turn causes diaphragm dysfunction and leads to smaller pulmonary volumes, greater metabolic demands on the respiratory musculature and increased airway resistance resulting from a reduction in lung volumes and further increases the work of breathing. Also due to truncal fat, there is reduced

Corresponding Author:

Dr. Ketki Ponde, Associate Professor, M.A.Rangoonwala College of Physiotherapy and Research, Azam Campus, Pune -411001, India. Contact: 9890993197,(020)26437871; Email: drketki85@gmail.com

ISSN: 2231-2196 (Print)

Received: 18.10 .2020
ISSN: 0975-5241 (Online)

Revised: 20.10 .2020
Accepted: 03.11.2020 
chest wall compliance. ${ }^{2}$ Also, the above factor causes respiratory muscles to develop fatigue during exercises.

Severely obese subjects tend to have a rapid shallow breathing pattern that results in increased oxygen cost of breathing. ${ }^{2}$ This in turn compromise leg blood flow thereby constraining oxygen uptake $\left(\mathrm{VO}_{2}\right)$ and limiting exercise tolerance. ${ }^{5}$ Respiratory muscle fatigue is a potential mechanism for impaired exercise tolerance. ${ }^{6}$ Thus, dysfunction in the ventilatory muscles can lead to hyperventilation, reduced exercise tolerance; reduced lung function which results in respiratory insufficiency along with increased work of breathing. This affects the muscle strength of inspiratory muscles. ${ }^{7}$ During exercise there is increased chest loading with reduced lung volumes and increased mechanical ventilatory constraints in obese individuals. This has been suggested as a possible explanation for impaired exercise performance in the obese and morbidly obese individuals. ${ }^{8}$ Increased body fat percentage also contributes to the reduction in the functional exercise tolerance. ${ }^{2}$ This evaluates Respiratory Muscle Strength (RMS) and exercises tolerance in such individuals of great clinical importance.

The strength of these ventilator muscles is analysed through measurement of maximum static mouth pressure (Maximal Inspiratory Pressure - MIP) against a closed airway. MIP is measured using a capsule sensing pressure gauze which is the easiest and non-invasive method of measuring the strength of respiratory muscles. ${ }^{2}$ Respiratory muscle training increases the strength and reduces the extent of fatigue of respiratory muscle hence improving their performance. Due to this, the metabolic requirement of inspiratory muscles during exercise decreases. This enhances $\mathrm{VO}_{2}$ dynamics resulting in improved exercise performance. ${ }^{6} \mathrm{~A}$ threshold device is a device used for the training of respiratory muscles. The threshold device contains a spring-loaded valve at one end and a mouthpiece on the other. The valve blocks airflow until the patient generates sufficient inspiratory pressure to overcome the resistance provided by the spring-loaded valve. ${ }^{9}$ Since respiratory muscles are also skeletal muscles, the more they are exercised the bigger and stronger they are expected to become. ${ }^{10}$

Exercise performance is assessed by measuring maximal oxygen uptake $\left(\mathrm{VO}_{2} \max \right)$ and 6-minute walk distance using 6-minute walk test. ${ }^{11}$ Various metabolic and respiratory changes take place during aerobic exercise; it increases the capacity to mobilize and oxidize fat and increases the levels of fat mobilizing and fat metabolizing enzymes resulting in favourable changes in body composition and reducing body fat along with regulating the accumulation of visceral adipose tissue. There is an increase in alveolar ventilation causing diffusion of gases (increase in $\mathrm{O}_{2}$ uptake and excretion of the excess of $\mathrm{CO}_{2}$ ) across the alveolar-capillary membranes which improves functional capacity and decreases ventila- tory demand and thereby improve overall pulmonary ventilation. ${ }^{12}$ Aerobic training improves contractility of the respiratory muscles thus resulting in improved respiratory muscles function \& strength. It may even increase respiratory muscle function as it increases Forced Vital Capacity (FVC) and Forced Expiratory Volume in 1 second -FEV1. ${ }^{2}$ During exercise, abdominal muscle relaxation at the end of exhalation facilitates inspiratory muscles. This places inspiratory muscles at an improved mechanical advantage, enabling them to generate more pressure at the onset of inspiration. Overweight and obese individuals with increased visceral adiposity and therefore increased waist circumference tends to focus more on weight reduction, neglecting the respiratory muscle training in the process of aerobic training schedule. ${ }^{2}$

\section{MATERIALS AND METHOD}

Institutional Ethics Committee approval was taken (IEC no: MARCOPAR/05/613) for the comparative study and written informed consent was obtained from the subjects after fully explaining the nature of the study. 60 subjects with BMI $23 \mathrm{~kg} / \mathrm{m}^{2}$ to $29 \mathrm{~kg} / \mathrm{m}^{2}$ (overweight and obese according to Asian classification $)^{4}$ of age $20-40$ years both males and females ${ }^{13}$ and individuals with MIP value less than $-80 \mathrm{~cm}$ $\mathrm{H}_{2} \mathrm{O}^{14}$ were included in the study. Subjects with a known case of respiratory and cardiovascular disorders, musculoskeletal disorders about thorax and lower limbs and individuals who were involved in any physical activity or sports activity or aerobic training $>2$ days a week during past 3 months ${ }^{2}$ were excluded from the study.

Participants were randomly allocated by chit method into 2 groups- Group A (24.20 \pm 4.11 years) and group B (22.87 \pm 3.85 years). Group A underwent an inspiratory muscle training programme along with aerobic exercise. Group B underwent aerobic exercise training alone. Both the groups had 30 subjects each.

\section{Study Procedure}

Maximal inspiratory pressure (PImax) - for obtaining respiratory muscle strength, capsule sensing pressure gauge with an operational interval of -250 to $0 \mathrm{cmH}_{2} 0$ was used. The calibration of equipment was tested assuring the reliability of the data collected. Intra- rater reliability was 0.962 and inter-rater reliability was $0.922 .{ }^{1}$ MIP values were obtained by asking the subject to do inspiration from residual volume (RV). The manoeuvre was sustained at maximal force for approximately one second and the highest value was computed from a minimum of three repetitions for each manoeuvre. Measurements were performed according to standard procedures. ${ }^{15}$

Exercise Performance -exercise performance was measured by calculating $\mathrm{VO}_{2}$ max and 6 Minute Walk Distance by using the 6 -minute walk test. ${ }^{16}$ 
Subjects were asked to walk with comfortable loose clothing and appropriate shoes, subjects performed 6-minute walk test in a $30 \mathrm{~m}$ corridor according to ATS guidelines.

a) The $\mathrm{VO}_{2}$ max was calculated using the following formula, ${ }^{16}$

$\mathrm{VO}_{2} \max =\mathrm{VO}_{2} \mathrm{~mL} \mathrm{~kg}^{-1} \min ^{-1}=(0.02 \times$ distance $[\mathrm{m}])$ $-(0.191 \times$ age $[\mathrm{yr}])-(0.07 \times$ weight $[\mathrm{kg}])+(0.09 \times$ height $[\mathrm{cm}])+\left(0.26 \mathrm{RPP} \times\left[10^{-3}\right]\right)+2.45$

b) 6-minute walk distance is the distance subject can walk in six minutes in their own comfortable pace without getting breathless.

Exercise protocol- Group A underwent IMT and aerobic exercise training for 5 days a week for 6 weeks. First IMT was given with a pressure threshold resistive device followed by aerobic exercises. Group B underwent aerobic exercise alone.

\section{Inspirational Muscle Training (Group A)}

\section{Instruction}

The subjects were in a sitting position on a chair with comfortable clothing. Nose clip was placed and subjects were asked to exhale completely and put the mouthpiece of the IMT in the mouth and inhale maximally to open the valve of the Inspiratory Muscle Trainer.

\section{Protocol}

IMT with a pressure threshold resistive training device was done. 5 sessions weekly for 6 weeks for Group A whereas Group B didn't perform any inspiratory muscle training. The initial training load was attempted at $40 \%{ }^{5}$ of the subject's baseline PImax for 7 minutes. Frequency of 3 sets of 10 breathes; with a rest period of 2 minutes between each set was done. After the first two weeks, PImax was increased to $60 \%$ of baseline PImax. After 4 weeks $80 \%$ of the subject's baseline PImax was achieved. ${ }^{11,18,19}$

\section{Aerobic Exercise (Group A and B)}

\section{Instruction}

The subjects were asked to wear loose and comfortable clothing and proper footwear. Borg's scale (6-20) was explained to the subjects to monitor the intensity of walking. The subjects were asked to walk on the level surface ground.

\section{Protocol}

Subjects were told to perform warm-up exercises for $5 \mathrm{~min}$ which consisted of all range of motion exercises (ROM) and marching for 1 minute. ${ }^{20}$

Aerobic exercise (walking): A moderate intensity (Borg's RPE $11-13$ ) exercise training was performed for 5 days a week for 6 weeks, during exercise training, the intensity was controlled by measuring Rate of perceived exertion of 11 -13 using Borg (6-20) scale. ${ }^{2}$ In the first two weeks, subjects walked for 20mins. Then it was progressed for 30 minutes in $3^{\text {rd }}$ and $4^{\text {th }}$ week. In the last two weeks, subjects were asked to walk for 40 mins. ${ }^{21}$ Cooldown was done for 5 minutes which included stretching of all major group muscles, each stretch was held 30 counts and two repetitions..$^{20}$

\section{Statistical Analysis}

Statistical analysis was done by using SPSS IBM version 20 (Statistical package for social sciences) All data in the study was presented as mean \pm standard deviation. the p-value of $\leq 0.05$ was considered statistically significant. Within the group, the comparison of the pre and post data was done by using paired t-test and between the two groups comparison was done using unpaired t-test. Demographic data of both the groups were comparable $(\mathrm{p} \geq 0.05)$ (Table 1)

\section{RESULTS}

The Respiratory Muscle strength (PImax) and exercise performance in terms of maximum oxygen uptake $\left(\mathrm{VO}_{2} \max \right)$ and 6 Minute Walk Distance (6MWD) of the participants of the group A and Group B were taken at the beginning $(0$ weeks)and the end of the six weeks.

Table 1: Pre and Post Treatment Comparison of 6 min walk distance; PImax and $\mathrm{VO}_{2}$ max of subjects of Group A(Inspiratory muscle training +Aerobic exercise)

\begin{tabular}{|c|c|c|c|c|}
\hline Group A & & Mean \pm SD & $\begin{array}{c}t- \\
\text { value }\end{array}$ & $\underset{\text { value }}{\mathbf{p}^{-}}$ \\
\hline $\begin{array}{l}6 \text { min walk } \\
\text { distance } \\
\text { (meters) }\end{array}$ & $\begin{array}{l}\text { Pre - Treatment } \\
\text { Post - Treatment }\end{array}$ & $\begin{array}{l}429 \cdot 43 \pm 47.15 \\
456.50 \pm 49.11\end{array}$ & 2.1779 & 0.0335 \\
\hline $\begin{array}{l}\text { PI Max } \\
\left(\mathrm{cmH}_{2} \mathrm{O}\right)\end{array}$ & $\begin{array}{l}\text { Pre - Treatment } \\
\text { Post - Treatment }\end{array}$ & $\begin{array}{c}43.67 \pm 9.12 \\
57.63 \pm 10.40\end{array}$ & $5 \cdot 5^{278}$ & 0.0001 \\
\hline $\begin{array}{l}\mathrm{VO}_{2} \mathrm{Max} \\
(\mathrm{mL} / \mathrm{kg} / \\
\min )\end{array}$ & $\begin{array}{l}\text { Pre - Treatment } \\
\text { Post - Treatment }\end{array}$ & $\begin{array}{l}17.96 \pm 2.01 \\
18.42 \pm 2.06\end{array}$ & 0.8754 & 0.3850 \\
\hline
\end{tabular}

Pre and post-treatment means were analyzed by performing paired t-test. There was statistically significant improvement seen in 6 min walk distance ( $p$ value $=0.0335)$ and PI $\max (p$ value $=0.0001)$ whereas $\mathrm{VO}_{2}$ max did not show any difference $(p$-value $=0.3850)($ Table 2$)$. 
Table 2: Pre and Post Treatment Comparison of 6 min walk distance, PImax and $\mathrm{VO}_{2}$ max of subjects of group B (Aerobic exercise only)

\begin{tabular}{llccc} 
Group B & Mean \pm SD & $\begin{array}{c}\mathbf{t}- \\
\text { value }\end{array}$ & $\begin{array}{c}\text { p- } \\
\text { value }\end{array}$ \\
$\begin{array}{l}6 \text { min } \\
\text { walk } \\
\text { distance } \\
\text { (meters) }\end{array}$ & $\begin{array}{l}\text { Pre - Treatment } \\
\text { ment }- \text { Treat- }\end{array}$ & $\begin{array}{l}449.97 \pm 52.95 \\
1.0324\end{array}$ & 0.3062 \\
$\begin{array}{l}\text { PIMax } \\
\left(\mathrm{cmH}_{2} \mathrm{O}\right)\end{array}$ & $\begin{array}{l}\text { Pre - Treatment } \\
\text { Post - Treat- } \\
\text { ment }\end{array}$ & $47.27 \pm 54.04$ & & \\
$\mathrm{VO}_{2} \mathrm{Max}$ & Pre - Treatment & $17.53 \pm 14.31$ & 1.1562 & 0.2523 \\
$(\mathrm{~mL} / \mathrm{kg} /$ & Post - Treat- & $18.17 \pm 1.81$ & 0.6309 & 0.5306 \\
$\mathrm{~min})$ & ment & & & \\
\hline
\end{tabular}

Pre and post-treatment means were analyzed by performing paired t-test. There was no statistically significant difference in pre and post-treatment values of 6 min walk distance (pvalue $=0.3062)$, PImax ( $\mathrm{p}$-value $=0.2523)$ and VO2 Max (pvalue $=0.5306)($ Table 3$)$.

Table 3: Comparison of 6 min walks distance, PI Max and $\mathrm{VO}_{2}$ Max between subjects of Group $\mathrm{A}$ and Group B

\begin{tabular}{|c|c|c|c|c|}
\hline Mean Difference & & Mean \pm SD & $\begin{array}{c}t- \\
\text { value }\end{array}$ & p-value \\
\hline \multirow{2}{*}{$\begin{array}{l}6 \text { min walk dis- } \\
\text { tance (meters) }\end{array}$} & Group A & $27.07 \pm 9.49$ & \multirow{2}{*}{5.7190} & \multirow{2}{*}{$0.0001^{*}$} \\
\hline & Group B & $14.27 \pm 7.76$ & & \\
\hline \multirow[t]{2}{*}{ PI $\operatorname{Max}\left(\mathrm{cmH}_{2} \mathrm{O}\right)$} & Group A & $13.97 \pm 4.82$ & \multirow[b]{2}{*}{10.218} & \multirow{2}{*}{$0.0001^{*}$} \\
\hline & Group B & $4.27 \pm 1.95$ & & \\
\hline \multirow{2}{*}{$\begin{array}{l}\mathrm{VO}_{2} \mathrm{Max}(\mathrm{mL} / \mathrm{kg} / \\
\min )\end{array}$} & Group A & $0.46 \pm 0.24$ & \multirow{2}{*}{3.0419} & \multirow{2}{*}{$0.0035^{*}$} \\
\hline & Group B & $0.29 \pm 0.19$ & & \\
\hline
\end{tabular}

Pre and post-treatment means were analyzed using unpaired t-test Group A showed statistically significant improvement in 6 min walk distance ( $\mathrm{p}$ value $=0.0001$ ), PImax ( $\mathrm{p}$ value $=$ $0.0001)$ and $\mathrm{VO} 2 \max (\mathrm{p}$ value $=0.0035)$ when compared with group $\mathrm{B}$

\section{DISCUSSION}

The purpose of this study was to compare effects of aerobic exercises along with inspiratory muscle training and aerobic exercises alone on respiratory muscle strength (PImax) and exercise performance $\left(\mathrm{VO}_{2}\right.$ max and six-minute walk distance). The study was conducted on 60 subjects who were divided into two groups, group A underwent inspiratory muscle training along with aerobic exercises and group B performed only aerobic exercises for 6 weeks.
Group A showed statistically significant improvement in PImax and 6-minute walk distance post-intervention as shown in table 1. Group B did not show statistically significant improvement in 6MWD, PI max and $\mathrm{VO}_{2}$ max as shown in table 2. When group A and B were compared, group A showed better results than group B as shown in table 3 .

Altered respiratory mechanics in overweight and obese individuals is due to the accumulation of visceral adipose tissue. As aerobic exercises were performed by both the groups, aerobic exercises might have helped in decreasing the body fat and regulating the accumulation of visceral adipose tissue, thus improving functional capacity. This may contribute to improving 6MWD and $\mathrm{VO}_{2}$ max in both the groups. ${ }^{2}$

A study conducted by Sonam Daftari ${ }^{2}$ "Effect of aerobic exercises on respiratory muscle strength in overweight and obese individuals" stated that in the early phase of the training period, during aerobic exercises, to fulfil the increased ventilatory and metabolic demands, the diaphragm had to work against the resistance posed by the visceral adiposity. As visceral adiposity is commonly found in obese individuals, this would overload and trigger the increase in the activity of respiratory muscles causing its conditioning and thus increasing the Respiratory Muscle Strength. ${ }^{2}$ As after few weeks of aerobic exercises, visceral adiposity is considered to have decreased, the diaphragm would have worked in a mechanically advantageous position. ${ }^{2}$ This might result in improved PImax seen in both groups.

Due to aerobic exercise, there is an increase in aerobic enzyme levels and oxidative capacity of the respiratory musculature. Aerobic training also increases inspiratory muscle capacity to generate force and sustain a given level of inspiratory pressure. ${ }^{22}$ Improvement in $\mathrm{VO}_{2}$ max in both groups as seen in table $1 \& 2$ may be due to aerobic training effect, which probably may be due to improved cardiac output, pulmonary diffusion capacity, alveolar-ventilation-to-perfusion ratio, Increase in oxygen extraction and utilization by the working muscles thus improving its efficiency, increase in capillary density, increase in muscle myoglobin content which might have increased the rate of oxygen transport and possibly the rate of oxygen diffusion to the mitochondria, increase in lactate threshold at sub-maximal workload and oxidative potential of muscles, thus improving the muscles metabolic function. ${ }^{2,23}$ These could be the possible reasons for the increase in respiratory muscle strength and exercise performance after aerobic exercises in both groups in our study.

Additionally group A underwent inspiratory muscle training program. Like other skeletal muscles, after training of inspiratory muscles, there is an improvement in the strength of inspiratory muscles. In obese individuals there is increased load on the diaphragm which leads to fatigue of the diaphragm, thus there is the recruitment of accessory muscles. 
IMT is proven to reduce fatigue of diaphragm which in turn reduces the recruitment of accessory muscles and also improves the pattern of recruitment of diaphragm muscles. ${ }^{11,24}$ This may be the possible reason for improved respiratory muscle strength in group A as shown in table 1.

Some studies have reported greater quantities of type II muscle fibres and smaller quantities of type I fibres in obese individuals. ${ }^{25}$ A study conducted by Alba Rami'rez-Sarmiento ${ }^{18}$ demonstrated that the external intercostal muscles of patients with COPD can express structural remodelling after specific inspiratory training. Both the proportion of type I fibres and the size of type II fibres were found to increase after training. ${ }^{18}$ So, the possible reason for the increase in respiratory muscle strength (PImax) in our study could be the structural remodelling of type I and type II fibres of the external intercostal muscle.

As inspiratory muscle training and aerobic exercises results in an improvement in respiratory muscle strength this also helps in improving exercise performance in three ways: A. Reduce overall exercise energy demands because of less respiratory work; B. reduce lactate production by the ventilatory muscles during intense, prolonged exercise's. Enhances the circulating lactate as metabolic fuel. ${ }^{22} \mathrm{~A}$ study was done by Stephen J. Bailey about the effect of IMT on pulmonary kinetics and exercise tolerance in healthy human states that fatigue of the inspiratory muscles occurs due to accumulation of fatigue-related metabolites including lactic acid which stimulates diaphragm innervating metaboreceptors. This activates meta bore flex invoking sympathetically mediated vasoconstrictor outflow and a reduction in limb blood. ${ }^{6}$ They observed reduction in blood lactate accumulation during the first 6 min of severe exercise after IMT, which may be, in part, due to the reduced inspiratory muscle fatigue. ${ }^{6}$

It is hypothesized in one of the review article by A Willian Sheel that during exercise the Respiratory muscles compete with limb locomotor muscles for their share of cardiac output. When the work of breathing is reduced, blood flow to exercising legs is increased and endurance performance is increased. While inspiratory muscle training decreases the work of breathing and perception of respiratory exertion, this may contribute to improved exercise performance..$^{26}$ Improving inspiratory muscle performance may improve ventilatory capacity and thus increases exercise performance in patients with chronic airflow limitation. ${ }^{9}$ Same may also be true in our study where improvement in ventilatory capacity might have resulted in better improvement in exercise performance in the group performing additional inspiratory muscle training.

These all can be possible reasons for better improvement in exercise performance in group A as compared to group B which shows that adding inspiratory muscle training to aerobic exercises improves inspiratory muscle strength and exercise performance in overweight and obese individuals.

\section{CONCLUSION}

Adding IMT to conventional walking program improved subjects inspiratory muscle strength and their exercise performance.

\section{ACKNOWLEDGEMENT}

Authors acknowledge the immense help received from the scholars whose articles are cited and included in references to this manuscript. The authors are also grateful to authors/ editors/publishers of all those articles, journals and books from where the literature for this article has been reviewed and discussed.

\section{Conflict of Interest: NIL}

Financial Assistance: NIL

\section{REFERENCES}

1. Karla L. Magnani, Antonio J. Cataneo. Respiratory muscle strength in obese individual and the influence of upper-body fat distribution. Sao Paulo Med J 2007;125(4):215-219.

2. Alberga AS, Prud'homme D, Sigal RJ, Goldfield GS, Hadjiyannakis S, Phillips $\mathrm{P}$, et.al Effects of aerobic exercise training on respiratory muscle strength in overweight and obese individuals. Int J Ther Rehabil Res 2015; 4(5):305.

3. Pradeepa R, Anjana RM, Joshi SR, Bhansali A, Deepa M, Joshi PP, et.al. Prevalence of generalized \& abdominal obesity in urban \& rural India-the ICMR-INDIAB Study (Phase-I)[ICMRINDIAB-3]. Indian J Med Res 2015;142(2):139-150.

4. Misra A. Ethnic-specific criteria for the classification of body mass index: a perspective for Asian Indians and American Diabetes Association Position Statement. Diabetes Tech Ther. 2015 Sep 1;17(9):667-671.

5. Bailey SJ, Romer LM, et.al Inspiratory muscle training enhances pulmonary O2uptake kinetics and high-intensity exercise tolerance in humans. J Appl Physiol 2010;109(2):457-468.

6. Villiot-Danger JC, Villiot-Danger E, Borel JC, Pépin JL, Wuyam $\mathrm{B}$, Vergès $\mathrm{S}$. Respiratory muscle endurance training in obese patients. Int J Obes 2011;35(5):692.

7. Salome CM, King GG, Berend N. Physiology of obesity and effects on lung function. J Appl Physiol 2009;108(1):206-211.

8. Dreher M, Kabitz HJ. Impact of obesity on exercise performance and pulmonary rehabilitation. Respirology 2012;17(6):899-907.

9. Retharekar S, Mundada N. Effect of respiratory muscle training as an adjunct to conventional therapy in phase 1 cardiac rehabilitation for median sternotomy patients. Int J Ther Rehabil Res 2015; 4(5): 305-311.

10. Dassios T, Katelari A, et.al. Aerobic exercise and respiratory muscle strength in patients with cystic fibrosis. Respir Med 2013;107(5):684-690.

11. Lisboa C, Villafranca C, Leiva A, Cruz E, Pertuzé J, Borzone G. Inspiratory muscle training in chronic airflow limitation: effect on exercise performance. European Resp J 1997;10(3):537-542.

12. Agre S, Agrawal R, Alirajpurwala A. Screen time evaluation, association with obesity, and cardio respiratory fitness among children aged 10-12 years. Indian J Child Health 2019:6(7):361364 . 
13. Kalra S, Unnikrishnan AG. Obesity in India: The weight of the nation. J Med Nutr Nutrac 2012;1(1):37.

14. Evans JA, Whitelaw WA. The assessment of maximal respiratory mouth pressures in adults. Resp Care 2009;54(10):13481359.

15. Gosselink R, Wagenaar RC, Decramer M. Reliability of a commercially available threshold loading device in healthy subjects and in patients with chronic obstructive pulmonary disease. Tho$\operatorname{rax} 1996 ; 51(6): 601-605$.

16. Caruso P, Friedrich C, Denari SD, Ruiz SA, Deheinzelin D. The unidirectional valve is the best method to determine maximal inspiratory pressure during weaning. Chest 1999; 115(4):10961101.

17. American College of Sports Medicine. ACSM's guidelines for exercise testing and prescription. Lippincott Williams \& Wilkins; 2013 Mar 4.

18. Venkatesh N, Thanikachalam S, Satyanarayanamurty J, Maiya A. Six minute walk test: a literary review. Sri Ramachandra J Med 2011;4(1):30-34.

19. Ramírez-Sarmiento A, Orozco-Levi M, Guell R, Barreiro E, Hernandez N, Mota S, et.al. Inspiratory muscle training in patients with chronic obstructive pulmonary disease: structural adaptation and physiologic outcomes. Am J Resp Crit Care Med 2002;166(11):1491-1497.

20. Enright SJ, Unnithan VB. Effect of inspiratory muscle training intensities on pulmonary function and work capacity in people who are healthy: a randomized controlled trial. Physical Ther 2011; 91(6):894-905.

21. Shah HJ, Kothary K. Supervised exercise versus workout videos for weight reduction in adults between age group of 20-50 years. Int J Physiother Res 2017;5(6):2534-2540.

22. Andersen RE, Wadden TA, et.al Effects of lifestyle activity vs structured aerobic exercise in obese women: a randomized trial. JAMA 1999;281(4):335-340.

23. McArdle WD, Katch FI, Katch V. Exercise physiology: nutrition, energy, and human performance. Lippincott Williams \& Wilkins; 2010.

24. Kaufman C, Kelly AS, Kaiser DR, Steinberger J, Dengel DR. Aerobic-exercise training improves ventilatory efficiency in overweight children. Paediatr Exerc Sci 2007;19(1):82-92.

25. Dall'Ago P, Chiappa GR, Guths H, Stein R, Ribeiro JP. Inspiratory muscle training in patients with heart failure and inspiratory muscle weakness: a randomized trial. J Am Coll Cardiovas 2006;47(4):757-763.

26. Magnani KL, Cataneo AJ. Respiratory muscle strength in obese individuals and influence of upper-body fat distribution. Sao Paulo Med J 2007;125(4):215-219.

27. Sheel AW. Respiratory muscle training in healthy individuals. Sports Med 2002;32(9):567-581. 